\title{
Reflections on Textual Editing in the Time of the History of the Book
}

Wim Van Mierlo

A FUNDAMENTAL ISSUE frequently discussed in textual scholarship is the relationship between "text" and "work". Since the emergence of the History of the Book, a third term must be taken into consideration too: the "book". As a field of inquiry that is by its own admission incredibly diverse, the History of the Book encompasses multi-disciplinary and multi-cultural approaches to the study of the book and of the production and dissemination of all written and recorded knowledge. According to David Finkelstein and Alistair McCleery, book history aims "to study all aspects of the creation of books" whether as "physical artefacts" or objects with "unique cultural symbols" $(2005,5)$, an undertaking that has its roots firmly in the traditional bibliographical disciplines such as descriptive and analytical bibliography and textual criticism.

To these forms of study, book history added a new layer of social and socio-economic history that began with the paradigm-shifting work of D. F. McKenzie in the ground-breaking essay "The Printers of the Mind" (1969) and culminated in his Panizzi lectures collected in Bibliography and the Sociology of Texts (1999). In that early essay McKenzie not so much challenged traditional analytical bibliography as expanded it, when he showed how knowledge of printing-house practices in seventeenth- and eighteenth-century England by using quantifiable evidence from printing catalogues, accounts' ledgers and business correspondence could significantly improve our bibliographical understanding. His emphasis on the conditions of book production, moreover, indicated a breaking away from the study of the individual book or text to books plural. With that not just the production of literature, but the production of all books and their dissemination fall within the purview of the history of the book.

\footnotetext{
"The Printers of the Mind", originally published in Studies in Bibliography, is reprinted in McKenzie 2002, 13-85. The Panizzi Lectures were delivered at The British Library in 1985.
} 
In the first instance, book history investigates the economic support structures that existed to bring these commodities to the reader — from book designs to marketing tools, from pricing mechanisms to the means of transportation. But books are also cultural products that help with the exchange of knowledge and ideas across time and space, and thus the production and reception of books play an essential role in shaping (as well as being shaped by) historical mentalités (Willison 2006, 2-3). The book, in other words, is no longer only the subject of bibliographical analysis, but sits at the nexus of a broad spectrum of economic, intellectual, social and cultural investigations.

In my introduction to Textual Scholarship and the Material Book, I pointed out that textual scholarship and book history share the book as an object of study but look at it from different perspectives, and attempted a broad characterization of the relationships between the two fields (Van Mierlo 2007, 4-5). In the present essay, I wish to deepen my inquiry into this relationship by looking at the directions textual editing has taken since the sociological turn in Anglo-American textual scholarship introduced by D. F. McKenzie and Jerome McGann and the emergence of book history. ${ }^{2}$ What potential there is for further cross-fertilization rests in particular on the concepts that McKenzie and McGann introduced in their work. Each in his own way placed the "book" alongside the "text". McGann did this conceptually when he distinguished between the linguistic code of a work and its bibliographical code (McGann 1991, 13 and passim). McKenzie more directly linked the "integrity of the text", which the textual editor seeks to preserve or restore, with "the formal unity of the book" which embodies that text (McKenzie 1999,

2 Insofar as this essay is concerned with the history of the book in textual scholarship, its counterpart - the importance of textual scholarship, and particularly textual editing, for the history of the book - deserves consideration as well. Ian Willison has argued that if the importance of book history to the development of the humanities is to continue further, book historians must consolidate their research procedures and scholarly practices, which include "technical" practices such as textual editing and archival research $(2006,13-15)$. To achieve this it must become necessary to reorient the importance of textual and bibliographical analysis and, rather than seeing them as origins from which book history developed, give them new pertinence. Given the complexities of this exercise, not in the least because textual scholars tend to focus on individual texts and works, I reserve dealing with this matter for another occasion. 
35). One outcome of their thinking in my view is that the same work - the same text even - can exist with differing degrees of granularity. The sort of text that you find in Project Gutenberg, for example, has a very low granularity, while that same text in its original first edition or in a de luxe format especially produced for the book collector has a high granularity. I contend that this granularity of the text is an aspect of bibliographical investigation that editors have not yet quite reckoned with.

For many scholars, rather, the question remains as to how the sociological turn, despite the obvious and inherent value of the insights it has produced, is at all relevant to the textual editor's work. ${ }^{3}$ How does one edit socially? To answer this question we must revisit some of the underlying assumptions at work in textual editing, which is tantamount to asking again what editions purport to do and who they are for, an issue I will return to towards the end of this essay. The Anglo-American editorial tradition, aiming to produce authoritative editions that ideally reflection authorial intention, produces scholarly editions in which the edited text is foregrounded over the transmission history of that text. When it comes to social editing, In other words, it is not that this approach is logically impossible, but that it is considered incompatible with accepted author-centred theories. I will argue that this need not be so; in fact, McKenzie's own practice in his posthumous edition of William Congreve proves otherwise. What is needed, therefore, is a consideration of the nature of work, text and book that realigns the sociological turn with the business of editing. As such, this essay is both about editing and editions, about the scholarly practice of textual criticism and the intellectual endeavour that makes our literary heritage available to the reading public.

3 Tanselle, for example, for the most part resists the relevance of a sociological approach in editing. While the the socially produced text may be of considerable historical relevance, textual scholarship cannot avoid concerning itself with the authorially intended text precisely because of the difference between the author's conception of his work and how that work evolved in production. Editing socially is permissible as an option, but for Tanselle the stakes of recovering an authorially intended text are simply higher: the one is matter of minor intervention in specific historical instantiations of the work; the other "requires acts of informed critical judgment" (2005, 171, 214). 


\section{The sociological turn in textual scholarship}

To bring about this realignment, I will draw on recent discussions in the area of digital text and scholarly digital editions about the notion of the interface. These discussions take place in the wake of the sociological turn in textual scholarship and the new ways of thinking about text it has brought about.

As textual scholarship became more interdisciplinary in the 1980s, it was also moving, so it seemed, beyond the core business of correcting texts according to well-established scholarly principles. The history of the Society for Textual Scholarship in the United States reflects this evolution. New theoretical perspectives meant there was a decrease interest in pure analytical and descriptive bibliography and a rising concern with questioning what "text" was in the first place. At the same time, the notion of final authorial intention was being slowly displaced. The outcome of this evolution was that textual scholarship became something of a broad church where the study of textual phenomena flourished as a goal in its own right.

Out of these new developments, and in reaction to the abstract notions of "texts" bandied about loosely in critical theory, emerged an increased interest for textual materiality. Terms like "material text", "material philology", and "textual culture" all indicated that texts are more than disembodied vehicles of meaning, but that instead they exist in specific socio-economic contexts and possess physical attributes, and that they come into being through the action of various agencies that include not only the author but also the publisher, typesetter, editor, marketing director, censor and so on. ${ }^{4}$

4 In the UK alone no less than three research centres devoted to material text have sprung up in recent years. Between 2005 and 2007 the then Centre for Publishing Studies at the University of Stirling ran a short series of conference and an M. Res degree in textual cultures (see http://www.textualculture.stir.ac.uk/index.html). In Cambridge the Centre for Material Texts was founded in 2009 (see their blog at http://www.english.cam.ac.uk/cmt/). In 2011 the Material Texts Network was set up at Birkbeck College, University of London (http://www.bbk.ac.uk/arts/our-research/centres/the-materialtexts-network). Others like exist around the world, such the Electronic Textual Cultures Lab (Victoria, Canada established in 2008), the centre for Materiale Textkulturen at Heidelberg (established in 2012, see http://www.materialetextkulturen.de) and the Textual Cultures group of the Research Institute for History and Culture at the University of Utrecht. In the United States even the Society for Textual Scholarship followed suit when in 2004-5 it broadened its 
The variety of approaches and research agendas that have emerged are almost always interdisciplinary. New research advocates "new perspectives, practices and technologies, which will transform our understanding of the way that texts of many kinds have been embodied and circulated" ("Welcome to the Cambridge Centre for Material Texts") and endeavour to frame the materiality of the text in new theoretical understandings at the junction where history, culture and literature come together (Material Texts Network). The influence of book history is evident, because "book historians are increasingly framing their work in terms of 'mediation', shifting the emphasis from recovering exact meanings in text to understanding the place of texts within contemporary society" (Finkelstein and McCleery 2005, 27).

Not infrequently, however, these new approaches are being framed in direct opposition to the perceived normative functions of traditional philology and textual editing. Textual editing, far from being on the wane, is undergoing some significant changes too. The idea of a "definitive" edition now seems long behind us (at least in certain quarters). For a while it was replaced by an enthusiasm for the everyone-his-own-editor movement inspired by the power of hypertext. But that wave too has now fortunately passed. The most radical change, however, is coming from the digital humanities. Scholarly digital editions, far from having made editing obsolete, are leading us into exciting new directions, while respectfully keeping an eye on the traditions that they inherited from printed scholarly editions. Indeed, digital editions require scholars to think again about what is at stake in textual editing (Galey 2010, 100-101). New technological possibilities are creating new ways of understanding what text is,

Rethinking the relationship of form to content in digital humanities - a relationship that was almost completely bypassed in theories about hypertext - Alan Galey considers the function of the interface as having a "granularity" that places itself between "material form" and "idealized content" (Galey 2010, 93-94; see also Kirschenbaum 2002, 20-27). Galey's remarks about the design of digital tools equally apply to printed books, whose granularity is what separates them from "plain" text. Just as with the digital medium, the "interface" of the book - its design, layout and typography — uses an

remit to all inquiries into the nature of "textuality" and changed its journal's title from Text to Textual Cultures (Storey 2006, 3-4). 
aesthetic form to enable effective communication between writer and reader. For the most part, scholarly editing has ignored this granularity. The textual idealism that underpins the Anglo-American tradition in particular, in which the scholarly edition is meant to represent (or approximate) the ideal incarnation of the work, pushes the non-textual aspects of the book to one side and supplants the original bibliographic code with a new one.

Of course one must acknowledge that critical editing intervenes in the original text, which is deemed imperfect; a reconstruction of the text as the author intended it cannot take place without altering the material nature of that text. This paradox poses a serious difficulty for the social edition. Nonetheless, in order to imagine such editions we may need to temper the old idealism about text and think more strictly - as German textual editors do - along historical-critical lines. ${ }^{5}$ What is text without the thing that supports it? If scholarly editions are to be grounded in the history of textual transmission, they ought not to avoid the historical manifestations of the text. Editing in the time of the history of the book requires editors to acknowledge at the very least that texts do not exist on their own. ${ }^{6}$

\section{Texts are not books ${ }^{7}$}

Assuming for the moment that texts are material (as is the common view), what is text actually made of? Why is it that we cannot hold text in our hands? What in other words is the material text made of? There seems no satisfactory answer that does not go back to critical theory. ${ }^{8}$ For some commentators the expression "material text" is

5 Tanselle also implicitly aligns social editing with editing documents, as in the German tradition, rather than with editing works (2005, 212-13).

6 Roger Chartier makes the point that "it is essential to remember that no text exists outside of the support that enables it to be read; any comprehension of a writing, no matter what kind it is, depends on the forms in which it reaches the reader" $(1989,161)$.

7 For the following discussion, I am grateful to @ETreharne (Elaine Treharne), @nickmimic (Nicholas Morris) and @ praymurray (Padmini Ray Murray) for an informative conversation on Twitter on the im/materiality of text, all of whom have suggested further areas where matters get complicated, as in the case of oral text, the functionality of text and the difference between common use and scholarly terminology.

8 The notion that text is material itself relies on the notion that language 
simply a tautology (Chaudhury 2010, 2). However, I contend that the materiality of the text is not that self-evident. The belief that it is begins to unravel when we turn to the digital realm. Countering arguments that digital text, unlike normal text, is not material, Matthew Kirschenbaum rejects what he calls the "tactile fallacy", the supposition that digital text is not material because "you cannot reach out and touch them", and argues instead that physicality in the digital environment is as real as in the printed environment; just because digital text cannot be touched does not mean that its "computational variables" do not contain any bibliographic codes (Kirschenbaum 2002, 43). Yet rather than make a case for the physicality of digital text one can easily turn this argument upside down and argue against the physicality of all text. The tactile dimension does not lie in the text, but in the paper, the binding of the book or the indentation left by the metal type. Likewise, the bibliographical aspects do not exist in the text, but in such variables as the layout, imposition or gatherings. Material text, therefore, may well be an oxymoron rather than a tautology. ${ }^{9}$

To be fair to Kirschenbaum, he actually does not use the adjective "physical" at all. It still remains to be seen, therefore, how the immateriality of texts works. On the one hand, things need not have physical form in order to be real. Certainly, from a phenomenological as well as from a literary-critical point of view readers experience texts without necessarily being aware of the material features that surround them. On the other hand, texts are more than lexical codifications. If nothing else, texts are visual. They are substantialized by the application of ink to the page (or pixels on the screen, or inscriptions on the writing support), a materialization that allows the writer's message to be stored and conveyed to the reader across time and space. The point in other words is that texts are packaged in ways that may appear transparent to most readers, but that in fact

is material, something that can be seen and heard. The idea has its origins in Saussurian structuralist linguistics, whose binomial concept of language bisects the sign into signifier (form) and signified (meaning). As David Chandler remarks, however, the signifier for de Saussure was a sound-image rather than a form; the signifier was not a physical, but a psychological entity. Later theorists reclaimed its materiality (Chandler 2007, 16, 51-52).

9 Thus Shillingsburg: "[The text] is something that, although it exists in physical forms, is in some sense capable of existing in more than one form, and is, therefore, not itself physical but must be conceptual or symbolic" $(2006,14)$. 
they are not. One can define bibliographical codes - which are not textual in the sense that they are not meaning-bearing - as layers that support and structure the text. ${ }^{10}$ It is possible to strip away some of those layers, which does not at first sight affect the integrity of the text and its meaning, but reduces the granularity of the bibliographic codes. Imagine a black-and-white newspaper photograph of the Mona Lisa next to the original painting; then think of Hamlet in the First Folio and Hamlet on the Kindle, and the differences in granularity will become apparent.

Peter Shillingsburg helpfully reminds us that there is no universal agreement on what texts are: "By texts, for example, some scholars mean physical objects, some mean a series of signs or symbols (the lexical text), and some mean conceptualizations only" (2006, 12). In Resisting Texts, Shillingsburg differentiates between the "material text" and the "reception text"; the latter is not quite the "work" (for which he reserves the term "conceptual text") but the abstract mental construction the reader creates in the act of reading, whereas the former is the "union of linguistic text and document: a sign sequence held in a medium of display" (1997, 51-52, 81-82, 101). ${ }^{11}$ Text and document are thus different yet wholly interdependent. The text, in other words, is mediated through the book, which functions as its interface and from which it is inseparable. Like a tattoo it sits, as it were, underneath the skin.

The current e-Reader revolution makes the importance of interface and mediation clear. The term "e-Book" is of course a misnomer. As Christian Vandendorpe suggests, the metaphorical application of such words like "page" and "book" in the digital medium represent the strong and lasting legacy of the codex, though the parallel with the scroll may be more appropriate (Vandendorpe 2009, 13839, 164). More to the point for our argument, the texts Kindles and similar devices display have few of the bibliographical features - paratexts, typographical design and layout - that we normally associate with books. Kindles do not offer pure text - that is in fact

10 It may be à propos to think of the etymological connection between "code" and "codex" as well as the precise meaning of the verb codify, which the $O E D$ defines as "to reduce (laws) to a code; to digest" and "to reduce to a general system; to systematize".

11 German editors in this respect talk about "Textgestalt" [literally, text form] and "Textträger" [textual carrier]. 
impossible - but the layout of their texts certainly represents the lowest common denominator of page design.

That the Kindle is more text than book is demonstrated by a central aspect of the functionality of e-Readers: the capacity of text to reflow. Unlike the text in a pdf say, which is locked into place, the iterative text has no formatting constraints and its flexibility assures that the content adjusts itself to fit the size of the screen. Content creators can still to some extent control the formatting of the text using html and css, but the text is not restricted to one specific layout. ${ }^{12}$ Text flow is an important feature of any form of reading on screen. Web browsers allow users to change the layout to suit their needs: they can increase or decrease the font size, overrule stylesheets, and change other settings. The "Readality" extension for Firefox, for example, offers a tool that de-clutters the web page and reformats the text rendering it easier on the eye. Besides the display of text on the screen, digital devices primarily rely on text to reflow when content is exchanged between devices or platforms. The iterability of text is what makes operations like importing content into your Kindle, clipping text to Evernote or copying and pasting in Microsoft Word possible.

Of course, this iterative function of texts existed with earlier forms of copying too (by hand or by print). However, whereas these earlier forms required human agency and, consequently, risked corruption, digital reflow is automatic and error-free. Furthermore, the question of what is a copy in the digital world is an interesting issue. What distinguishes one copy of a text from another is the metadata, i.e., something linked with but separate from the text. Like all paratexts, metadata exist on the margins of the text. In the analog world, the metadata extend and include to the physical medium that carries the text. A copy of a text, errors notwithstanding, does not create a new text, but it does create a new a new document. Peter Shillingsburg therefore sees the property of iterability as a form reincarnation. The copy of a manuscript results in "two material objects each occupying a different space, though each purports to bear the same text" $(2006,13,14)$. In particular, Shillingsburg associates the reincarnation of the text with the editorial act.

12 With this freedom also come limitations. On the web, html is mostly inadequate to represent some finer aspects of typography (e.g., ligatures, tables) and devices like the Kindle are better suited to displaying prose than poetry. 
I do not want to push the argument about the im/materiality of texts any further, except to say that often people use the phrase "material text" when they actually mean "book", whose physical attributes are of course not in doubt. The book, therefore, has no iterative properties. Its physical form is unique and stable, and therefore cannot be "edited" in the normal sense of the word. Hence, there remains a challenge to define what role they play in textual editing.

\section{The granularity of the text}

McKenzie, more than anyone else in the field, has made the leap from text to book, advocating that we should amplify "our sensitivity to the printed book as physical form in order to refine our notions of the historicity of printed texts and our function in editing them" $(1984,334) .{ }^{13}$ A discussion of the nature of text and book cannot take place without reference to McKenzie's seminal idea that "forms effect meaning", a subtle but profound adjustment of the old structuralist idea that form and content are inseparable. ${ }^{14}$ What he means is not that bibliographical forms have meaning, but that they bring about meaning.

Certainly forms can also affect meaning, as Jerome McGann has argued in respect of his bibliographical codes. However, I am somewhat skeptical as to the ability of the bibliographical codes to bring about "shifts and changes" in meaning $(1991,59)$. The examples that McGann himself and other scholars have cited strongly support his arguments, but in each case the circumstances are exceptional and a general theory is more difficult to validate. What may be obvious for Byron's "Fare Thee Well", for instance, may not be so obvious with other works. James Joyce's Ulysses, for instance, which was serialized

13 Still, even McKenzie uses "text" as a shorthand for any kind of carrier of verbal and non-verbal communication (1999, 13). In common English usage, the words "text" and "work" are of course practically interchangeable, but without a doubt the pervasive use of "text" in literary scholarship, which has experienced a dramatic increase since the 1980 s, has left its mark too.

14 The depth of McKenzie's statement is adumbrated when we consider its misprint in the Routledge Book History Reader. "forms affect meaning", with an "a" rather than an "e" (Finkelstein and McCLeery 2006, 37; the error was first spotted by Galey 2010, 113-14). In English the words "effect" and "affect" are often confused. Obviously close to each other in sense and orthography, the first means to bring about something; the second to have an influence on. 
in two little magazines, The Egoist in England and The Little Review at the other side of the Atlantic, both from 1918 onwards, before it was published in book form by Sylvia Beach's Shakespeare \& Co (1922). The similarities of these two publications are probably greater than their differences. Despite looking very different, the two magazines were both aimed at the individualist, discerning and conscientiously modern reader. Both were partly orchestrated by the impresario of literary modernism, Ezra Pound, and occupied a niche in the literary market in England and the United States. They also shared a do-it-yourself attitude towards publishing that was later fulfilled by Beach when she offered, even though she had never ventured into publishing before, to bring out Ulysses.

McGann's conceptualization, appealing though it is, perhaps overdetermines the power of form. The circumstances in which Byron's poem was published - privately printed, twice pirated, and finally canonized in the 1816 Poems - show that not just the "look" of the printings but also their function and audience were different. The conditions in which other works were published may not have created such marked differences. I agree that different bibliographical codes may result in differentiation in meaning, but we should also ascertain whether these differences indeed registered in the minds of readers. To check this is a matter for reception history. ${ }^{15}$

I find McKenzie's point, therefore, more discerning. His argument is less about hermeneutics than about facilitating the transmission of texts and their meaning; it is about understanding that transmission from the evidence in the books themselves as well as from "conceptions of the book", the way printers expected readers to interpret the forms of their book designs. (McKenzie 2002, 207). Running headers, type size and other paratextual features of the book do not have any meaning in their own right; to appropriate a term from Roland Barthes, they are a zero degree of printing, unburdened by the need to communicate themselves. Nevertheless, they facilitate communication and the production of meaning. The aims of book design and typography thus involve "aesthetic sensibility, technically informed, serving the communication of meaning, the creation of the distinct experience of reading the work" (McKenzie 2002, 214). Functionality combined with aesthetics determine for McKenzie the

15 Evidence in the case of Byron's "Fare Thee Well" certainly suggests that the four versions were received differently. 
"book's total form", but the effect on meaning really depends on what "expressive resources" were "available to an author through his printer" (2002, 215-16). While it is the case that decisions about format were generally motivated by business practices (2002, 22021), McKenzie does not exclude agency and intention from book production, which is a very important point when it comes to textual editing.

The distinctive "typographic vocabulary" (McKenzie 2002, 218) of James Joyce's Ulysses may serve to illustrate the complexities of the book's "expressive resources". The only areas of the book's get-up in which Joyce was involved were the now famous pale blue colour of the cover and the white lettering of the title. Joyce requested several samples before he was satisfied that the tone of blue was right and evoked the colours of the Greek flag. Readers may have missed this vexillologic allusion, but they could not have failed to see (and heft) the book's bulk: the large-sized edition (state B) printed on vergé d'arches handmade paper ran to 732 pages and was approximately 46 $\mathrm{mm}$ thick. It was also a very fragile item as its weight easily caused the inner hinges to crack. On the inside, the layout was rather unusual. On the one hand, the classic Elzevir typeface, although it was probably chosen for its compactness, adds gravitas. The layout of the text, on the other hand, does not conform to the so-called Van de Graaf canon, which stipulates that the text area be proportional to the page size; the result is an imbalance between the position of the text area and the margins. ${ }^{16}$ The physical composition of the page thus almost acts as an impediment, creating a sense, compounded with the inherent difficulty of the novel itself, that this is a book that is difficult to digest, and prompting critical derision. George Slocombe in his Paris column in the Daily Herald of 17 March 1922 exclaimed: "And here it is at last, as large as telephone directory or a family Bible, and with many of the literary and social characteristics

16 Ulysses in "state B", printed on large-sized paper, measures $195 \times 225 \mathrm{~mm}$ and the text area $122 \times 164 \mathrm{~mm}$, with an inner margin of $30 \mathrm{~mm}$ and an outer margin of $46 \mathrm{~mm}$. To conform to the Van de Graaf canon, the triangle A-C in Figure 1 should pass through the bottom-left and top-right corner of the text area on the verso and the top-left and bottom-right corner of the recto; the cross formed by lines D-E and F-G should pass through the top left and top right corner of the text area; finally when line $\mathrm{H}-\mathrm{I}$ passes through the top-left corner of the text area on the recto, then the line I-J should finish where B-C and F-G intersect. 


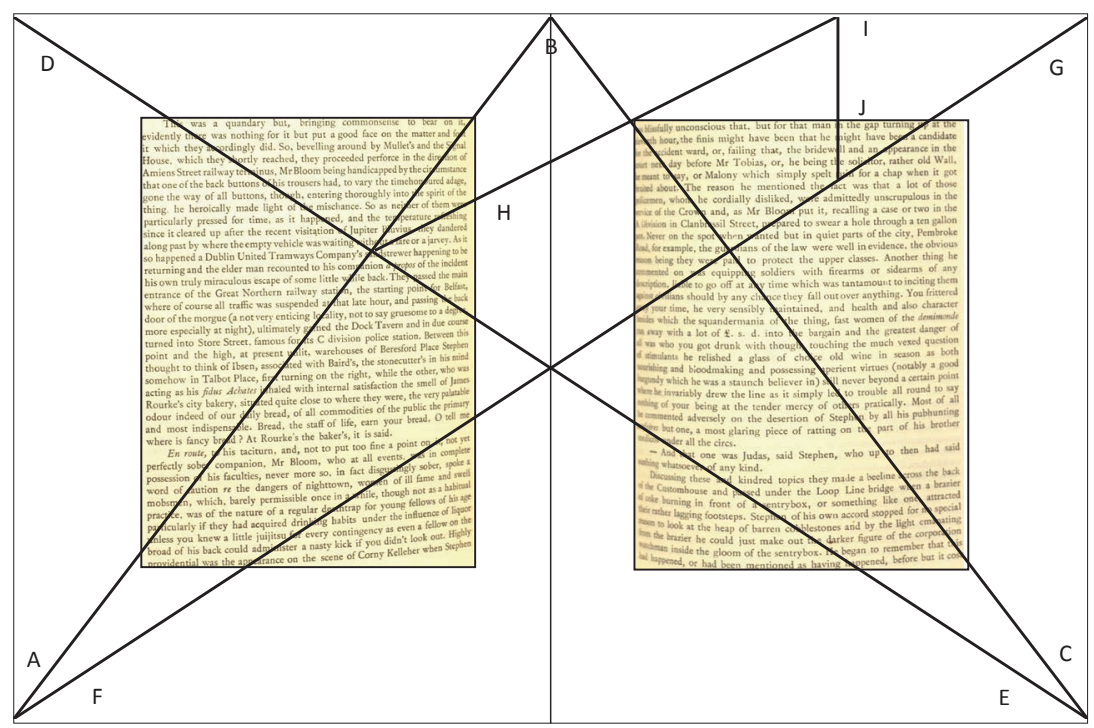

Figure 1: Van de Graaf canon. Mock-up of James Joyce, Ulysses (1922; state "B").

of each" (quoted in Deming 1997, 217). The format, however, was not intentional, but resulted from the challenges posed by Joyce's lengthy work.

For the textual editor, the challenge then lies in what to do with the bibliographical information, particularly in cases where typography itself has gone wrong. T. S. Eliot's The Waste Land is a case in point. Eliot's poem was published no less than four times as an individual poem: in October 1922 the poem appeared in the first issue of Eliot's new magazine The Criterion, followed a month later by publication in the American magazine The Dial; on 15 December Boni and Liveright of New York issued the first book publication with a print run of 1,000 copies; Virginia and Leonard Woolf's The Hogarth Press finished their hand-set edition of 460 copies almost a year later, on 13 September 1923. Citing Eliot's approval, most editors consider the text of the American edition to be the most reliable, and it has been used as copy-text in Lawrence Rainey's critical edition (Eliot 2006; see 46-48 for details). The Criterion text and the Boni text were almost certainly set around the same time from 
two different typescripts. ${ }^{17}$ Concerned about the form of the poem and other details, he warned Boni and Liveright upon sending the typescript: "I only hope the printers are not allowed to bitch the punctuation and the spacing, as that is very important for the sense" (2009, 1: 707). His worries, however, had been unwarranted, for when the proofs came back he thought they were "excellent" (2009, 1: 746). The same was not true for the proofs of The Criterion, which arrived a week later from the English printers. Clearly agitated, he complained to the magazine's publisher that the printer had had made a number of "undesired alterations". What these undesired alterations were is unknown, but one may assume that they consisted of changes to the punctuation and spacing. With considerable effort, Eliot reversed the errors and managed, in spite of a few misprints that remained, to create a text that principally matched his intentions. The affair, however, may have left him with a lingering dissatisfaction over The Criterion text, even though in the end it was the better version.

The reason is that while the Boni and Liveright text carries authority, its layout does not. Feeling that a poem of a mere 430 lines was not enough to fill a book, Horace Liveright, one of the firm's directors, had asked Eliot whether he could not add a few extra poems to pad out the book. Eliot objected, but produced instead the famous notes. The publishers, no doubt deliberately, chose a small, octavo format and printed the poem in large type with ample leading so that the whole in the end ran to a reasonable book of 64 pages. Owing to the reduced size, the printers had to turn most of Eliot's long lines, lending the poem, with the original spacing and line divisions almost completely lost, an air of even greater disjointedness than is actually the case. The Criterion text, by comparison, comprised only 15 pages of a larger format (height $c .23 \mathrm{~cm}$ ). Eliot's poetry, uninterrupted by line division, really comes into its own in this more spacious environment and has an orderly, almost classic

17 Whether the American typescript is among the four typescripts still extant is not yet known (see McCue 2006, 25). The Criterion typescript (a carbon copy with some autograph corrections) may be the one in the Hayward Collection at King's College Cambridge; it contains a handwritten note by Eliot in which he says that it was possibly used by the printer for The Criterion (MS CAM/ $\mathrm{HB} / \mathrm{TSE} / \mathrm{V} 4 \mathrm{a}$ ). However, about 10 lines were accidentally omitted as a result of an eye skip and remain uncorrected. 

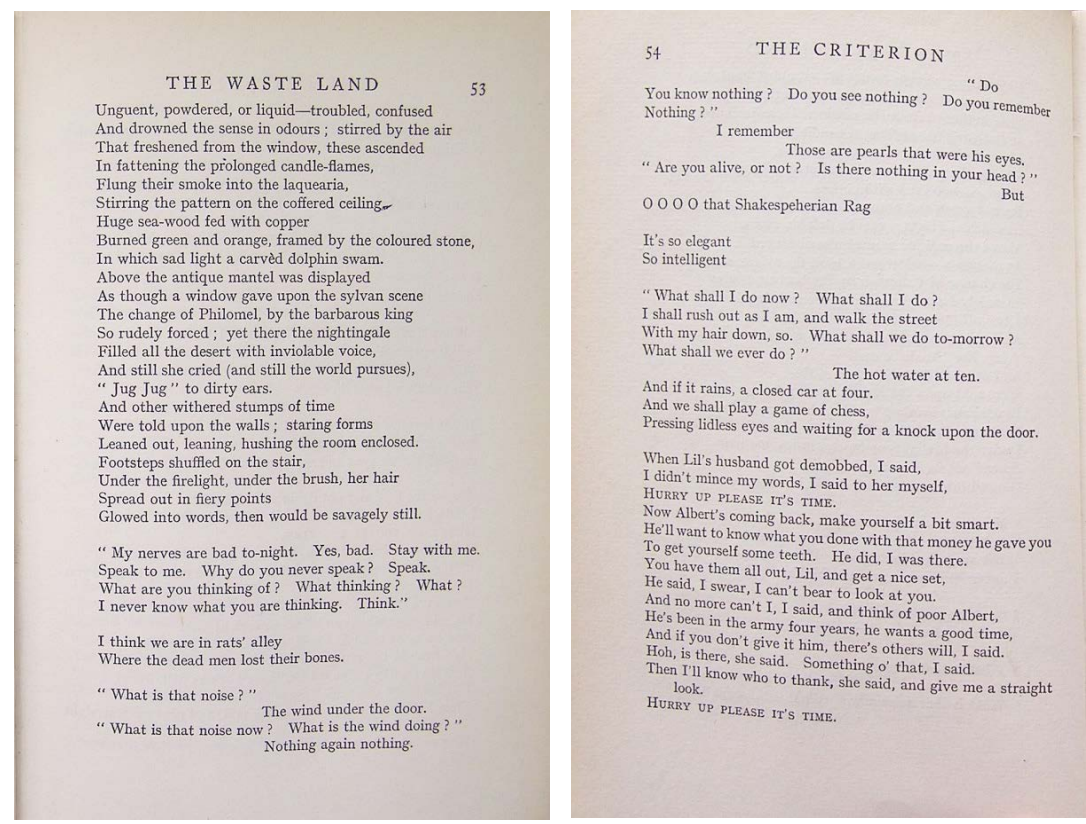

Figure 2: The Waste Land, "What is that noise", The Criterion I (1922), pp. 53 and 54 .

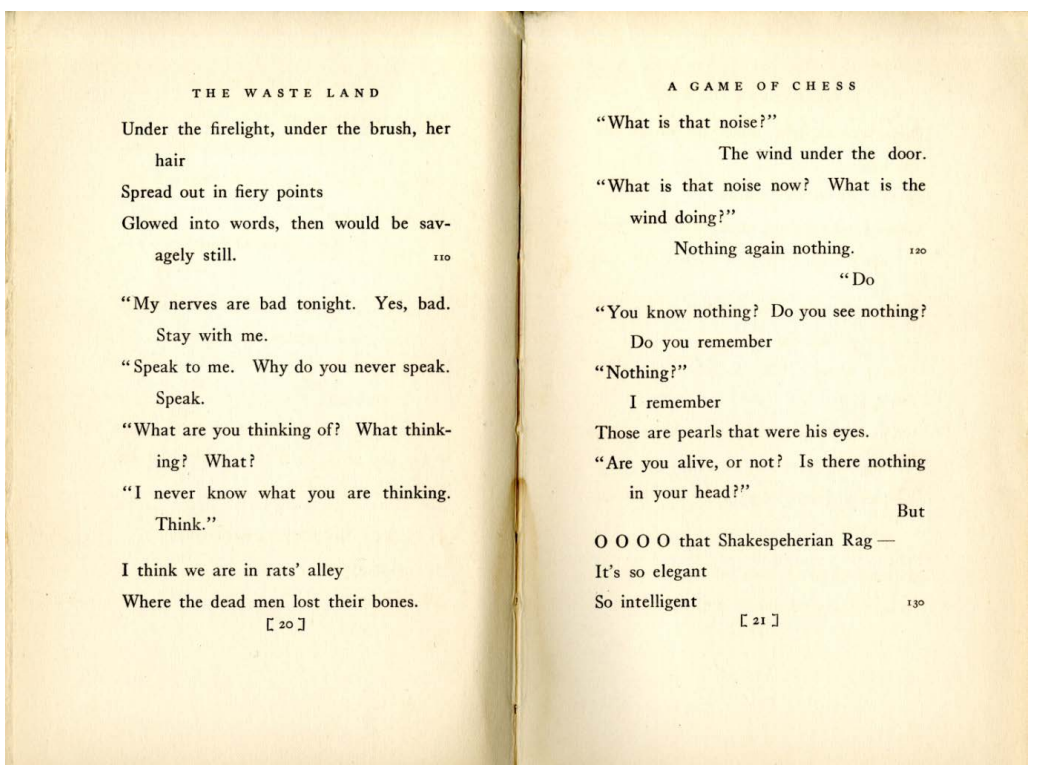

Figure 3: The Waste Land, "What is that noise", Boni and Liveright (1922), pp. 20-21. 
feel to it. ${ }^{18}$ The spacing, moreover, follows more closely the spacing in the typescript preserved at King's College Cambridge. In one particularly difficult passage, the text literally cascades down the page, a feature meant to convey typographically the anxiety of the speaker; The Criterion manages to replicate the intended shape, although it does not get it exactly perfect (Figure 2). None of the other early editions — the Dial and the Hogarth Press — does so either (and nor for that matter any of the later Faber editions of Eliot's Collected and Selected Poems). But in the Boni and Liveright the feature is lost entirely, and with the layout's expressive form (Figure 3). ${ }^{19}$

\section{Editions, their aims and audience}

The argument that books as carriers of texts are important for textual scholarship is largely self-evident. But how should it change our practice? Is the aim merely to produce scholarly editions with additional content, as Bodo Plachta (2007) has suggested? The case Plachta puts forward uses examples of "politically charged" paratexts to demonstrate the importance of book forms to the study of the production, dissemination (to stay under the radar of censorship, for example) and reception of printed texts $(2006,96,99)$. His recommendation to include facsimile materials in (digital) editions is not meant to replace textual criticism, but rather to add to it, so that the edition may also serve as an archive" while "offer [ing]

18 When almost a year Eliot thanked Virginia Woolf for the Hogarth Press edition, the first English book edition, he told her that he was "delighted": "Spacing and paging are beautifully planned to make it the right length, far better than the American edition" (2009, 2: 202).

19 Rainey further claims that the Boni and Liveright edition was used as copy-text for the Hogarth Press edition because Eliot considered it the best text (Eliot 2006, 47). This is, however, not the case. The famous Notes apart, which had only appeared in the Boni edition, a small number of substantive variants make it obvious that the Woolfs did not set their text from the American edition, but presumably from a typescript that was related to the typescript that was sent to New York. (The number of readings where the Hogarth text is not in agreement with the Boni text and that are not clearly the result of non-authorial intervention is very small.) The marked dissimilarity of the Hogarth edition's layout to that of the Boni and Liveright makes it quite obvious that the Woolfs did not use the American edition as their model. It would have been impossible for them to reconstitute the layout of the poem in accordance with Eliot's intention. 
urgently needed starting points for the use of editorial products in literary studies" $(2006,103)$. Of course, the practical implications of bringing the physical features of the book into the edition remain considerable, even in the electronic environment, no matter how better suited it may be to completist editions.

Textual editing in the time of the history of the book should, however, not simply be a matter of producing editions that have more content, but rather of editions that do more things. Such a reconceptualization of scholarly editions should go beyond the bipolarization created by the digital era: of having digital critical editions on the one hand and digital archives on the other. Shillingsburg has stated repeatedly that in order to fulfil his responsibility to the reader the task of the editor is to edit; editors "whose work stops at archiving perform valuable work, but they offer no more than starting places" (1997, 224). One might object that Shillingsburg takes a rather narrow view when he sees the digital archive only as a toolkit for making editions and not as a repository for the process of textual transmission; he certainly does not see the critical apparatus that way: rather than being "a dumping ground for superseded textual forms", the apparatus is "a guide to the progression of composition and production processes creating a succession of versions" $(1997,212) .{ }^{20}$ Digital archives are no doubt better adapted at providing this guidance than are the printed edition whose apparatus - mockingly dubbed a Variantenfriedhof [cemetery of variants] (see Gabler 2008, 14) — is often difficult to repurpose. Regardless of the painstaking accuracy with which apparatuses are put together, to reconstruct particular states from the welter of detail in them is laborious, if not impossible. Digital editions, by contrast, being both edition and archive, offer the potential for digging more deeply into the textual data.

Once it was enough for editions to present an accurate text and to provide a rationale for its emendations as well as a record of the textual history and transmission. But the objectives from the past no longer satisfy the editors of the digital era, whose scholarly editions

20 Shillingsburg of course is no adversary of digital archives, as long as they are both "an archive of historical documents whose iconography is intact" and "edited texts [...] produced to reflect the work of a historian [i.e,. critical editor]" that should be "introduced historically, critically, and textually" (1997, 24). 
are becoming richer, more ambitious and more diverse. One way that digital editions are moving beyond the print edition is that they no longer simply offer access to the textual data, but present "ways of filtering" that data that enable readers to interrogate the text's transmission history (Lavagnino 2009, 72). ${ }^{21}$ Furthermore, if we now agree that editions have only a limited life cycle before new theoretical perspectives and new research questions prompt us to remake our editions, then we must also acknowledge that not all editorial aims can be served by one edition alone. Even though we currently accept that having rival editions is good (since no edition can claim to be "definitive"), we still tend to see them as rivals for truth rather than as editions occupying different shares of the scholarly and readerly market .

Textual pluralism is good - as long as it furthers our understanding of the nature of text, work and book; it cannot simply be good for its own sake, or to make it fit a liberal humanist agenda. The point is that textual pluralism only becomes really insightful when we recognize the differences in purpose that editions serve and that different editions may have different users.

In some cases, it would seem that differences in purpose are better reflected in public controversies over editorial practice rather than in explanations about editorial rationales in the editions themselves. There are two rival critical editions of W. B. Yeats's poems: that by Richard Finneran, originally published in 1983, revised in 1989 and available in the Collected Works issued by Scribners in New York; and that by A. Norman Jeffares, published by Macmillan (but available only in the UK) (Yeats 1989 and 1997). Both editions apply the principle of final authorial intention, and as a result both editions agree on most readings. The editors agree on the meaning of the words "final" and "intention", but they disagree on the meaning of the word "authorial". For Finneran, Yeats is the author; his edition accepts only the final readings that Yeats authorized during his lifetime. The same is not true in the Jeffares edition. Warwick Gould,

21 For Lavagnino, the scholarly editions of the past were too concerned with access to information, rather than understanding that information; he feels that by focusing on the "activity of the editor", rather than that of the "user", too many editions "offered access to the wrong thing" (2009, 66). Not only was the apparatus side-lined, leading it to be overlooked by readers, but its function and workings were not adequately explained. 
who was Jeffares' collaborator, categorically rejects Finneran's view (Gould 1989). Yeats was of course the author of his poems for Gould too, but not so to speak the sole author. Using letters and other archival evidence, Gould demonstrates that Yeats delegated certain "final" decisions about his texts to other people, in particular to his editor at Macmillan, Thomas Mark, and to his wife, George Yeats. After Yeats's death, Mark worked closely together with Yeats's widow, who implemented revisions that Yeats had indicated he wanted but had never carried out (Gould 1994, 110-11). Gould, in other words, sees Yeats as a "social" author who was at the heart of a small network of people who all had some authorial input.

Apart from generating a handful of variant readings, this different conception of authorship has had significant impact on the order of the poems in Yeats's canon. When in 1933 Macmillan issued the Collected Poems containing all of Yeats's work to date in two volumes, Mark suggested a departure from the normal chronological order (an order which had already been established for the Edition de Luxe) in favour of a division between "Lyrical Poems" in volume one and "Narrative and Dramatic Poems" in volume two. Mark proposed this arrangement primarily for commercial reasons. To arrange the poems chronologically would have meant opening the volume with a long narrative poem called The Wanderings of Oisin, which Mark felt might put off potential buyers; placing the narrative poems in the second volume meant that volume one could open with the betterknown lyrics from Crossways (1889) and The Rose (1893), including the immensely popular "The Lake Isle of Innisfree". Yeats warmly welcomed Mark's suggestion (Gould 1989, 714-15). Since no other collected edition appeared during Yeats's lifetime, the order of the Collected Poems became, de facto, the poet's final intention and was thus followed by Finneran.

However, this is not the full story. As Gould argues, Collected Poems represents Yeats's canon for a particular time and audience: it served its purpose wonderfully as a trade edition, satisfying both old and new audiences while aiming for a sense of completion; but it deviated from Yeats's own vision of his canon, which did not marginalize the longer poems. During the 1930s, he was making preparations for no less than two de luxe editions of his collected works, one to be published by Macmillan in the UK and Ireland, the other by Scribner's in the United States. At no point was the new arrangement of 
Collected Poems, separating lyrical from narrative poems, considered for these editions (see, e.g., Gould 1989, 725). Unfortunately, neither edition ever appeared. Although they were not published, they exist in numerous runs of page proofs and draft contents, and therefore their authority supersedes that of the texts in the 1933 Complete Poems.

Yeats's poems are not just separate aesthetic entities, but exist within the larger constellation of his œuvre; as such, they cannot be separated from the book as physical object, to the extent that design and layout form an integral part of the symbolic structure of the poetry (though this dimension has not yet been realized in any existing edition). Yeats, moreover, not only frequently and obsessively revised his poems, he was apt to reconceive the total form of his body of work whenever a new publishing opportunity presented itself. More is at stake, therefore, than simply the words that constitute the text. Yeats's intentions are embedded in the social conditions that that supported the coming into being of his oeuvre - a process that invites us to recognize the dynamic interplay between text and work - whose realization involved agencies other than the poet himself.

What this example illustrates is not simply that different rationales lead to different editions, but that editors deal with more than just text. (While Finneran's edition is defensible in its application of accepted editorial principles, it is narrowly author-centred and does not encompass the full history of the textual transmission. Jeffares' edition uses a broader conception of authorial agency as well as a more complete textual history that gives credit to Yeats's collaborators in the creation of his text. Moreover, in arguing against Finneran, Jeffares' edition manages to clarify its own editorial purpose within the editorial landscape. Not only do different rationales lead to different editions; they also lead to different uses and fulfill different research needs.

While critical editions normally have a statement about editorial rationales, they generally do not show great self-awareness about the ideological value and impact of these aims. Eclecticism in the AngloAmerican world still all-too often produces editions allegedly suited to the needs of all readers. The norm still seems to be to accept "texts as given" (Gabler 2008, 14). The textual idealism that exists within the editorial tradition, whose aim it is to establish a text as the author would have wished it, also suffuses the discourse about scholarly 
editing. The term authoritative edition seems attached not to the soundness of the scholarship that went into its making but to the edition itself. It appears to suggest that its established text is authoritative, and therefore timeless, while the format of the edition and the way it presents the text, and the evidence for its critical emendation, is portrayed to be objective, transparent and neutral. The academic book market is complicit in this. Not only are popular series like the Norton Critical Editions and Oxford World Classics uncritical when they boast about offering the most "authoritative texts" (a nomenclature that is ambivalent at best, because most are simply reprints of what is considered the "best" text), but most academic publishers of scholarly editions also see their editions as offering 2-for-1: "an error-free, authorial, clear-text edition for the general reader and a repository of textual information for the specialist reader" (Egger 2009, 163). This attitude allows them subsequently to issue "light" versions that greatly condense or downright suppress the edition's paraphernalia (i.e., textual introduction and critical apparatus) on the grounds that students of literature have no interest in this. A selffulfilling prophecy if ever there was one.

Yet it is evident that the "interface" of the scholarly edition and the textual information it conveys is interpretive and highly mediated. According to Hans Walter Gabler, editions present "editorial arguments" and their design is "an achievement [...] of networking texts and knowledge" (Gabler 2008, 6). Interestingly, the language that Gabler uses is borrowed from the digital edition (although ostensibly it recalls the medieval tradition of marginal scholia), but he recognizes a problem as well: despite the "stringent formalisation" of the edition's "intellectual substance", the apparatus and commentary are relegated to the back of the edition. ${ }^{22}$ Editors nowadays generally accept that no edition can be definitive, and they acknowledge that their emendations are reasoned choices from the evidence available to them. But the editorial choices, even when they are appreciated in the spirit of textual pluralism, are too often seen

22 This displacement prompts John Lavagnino's criticism that the apparatus is too much a store-house for data, and not enough a tool for critical analysis; in his view, the emphasis of the scholarly edition should shift away "from the data to ways of filtering it, so as to put readers in the position not of asking for more but rather of finding ways to get just what they want" $(2009,70,72)$. 
as the product of scholarship, not as part of an on-going intellectual investigation into textual history.

At first sight, even McKenzie in his posthumous edition of the works of William Congreve did not fully implement his own conceptualization of the sociology of the text. Opting for the 1710 Folio edition of Congreve's Works as his copy-text instead of the first Quarto editions of the individual plays, McKenzie produced, by his own admission, an eclectic text based on final authorial intention. ${ }^{23}$ His preference for an authorially revised text over the historical context of its original production, however, was not simply motivated by editorial orthodoxy. In fact, the choice of copy-text was far from obvious given that Works was not without problems. Congreve in some cases relied on corrupted reprints for his own base text; he seems to have revised his texts in a rush (2011, xxxiii); and not all his revisions can be considered improvements, particularly not because, following increased pressure from Queen Anne's Court to quell licentiousness, Congreve submitted himself to self-censorship (2002, 224-25; 2011, xxi-xxii). What motivated McKenzie's choices, however, was the fact that Works was consciously fabricated as an cuvre. While its "historical form and concept" are just as valid as the "textual structures" of the original Quarto design, Congreve gave his plays a whole new intent. Congreve did more than just revise his texts; he regenerated their "textual structures" as he lifted them, as McKenzie puts it somewhat lyrically, "from the soil of [their] first growth" and replanted them "in new relationships". The Folio differs from the Quartos in that the individual plays have been given a new "display" [ that] is more likely to favour the design of the whole than the diverse forms of the earliest state of each item" (2011, xviii). The neo-classical design that he gave to this plays was not only an innovation for the time, the result of a close collaboration between Congreve, the bookseller and publisher Jacob Tonson, and Tonson's

23 Scholars have expressed surprise at McKenzie's seemingly conservative approach, but this is no doubt due to a misapprehension of what the sociology of texts means. Even Tanselle points out that "a socially edited text can contain unintended errors just as easily as can a text constructed by one person. Unless one wishes to refrain from all emendation of documentary texts, one is admitting the concept of intention" $(2005,288)$. Thus while McKenzie's editorial practice adheres to the editorial tradition of Greg, Bowers and Tanselle, this is not an argument against social editing; as my example from Yeats the social edition is possible and, in many cases, desirable. 
printer John Watts; it also approximates the "distinct unitary form" that Congreve used for scene divisions and stage groupings in some of his extant manuscripts (2011, xxiii; see also McKenzie 2002, 123-24). McKenzie, therefore, believed that for Congreve the Folio edition meant a typographical translation of the play text into the form of the book with the intent to create a "hand-held theatre" (2002, 201).

In an unexpected twist, however, McKenzie argues that the eclectic edition itself constitutes a "sensitive response to social [and historical] context" that "serve[s] the play to the fullest" (2002, 226).$^{24}$ Explicitly positioning himself against Hans Zeller, who sees eclecticism as a violation against the integrity of the text, he states: "Conflation is inevitable. But it is also critically and historically responsible only in so far as the causes of the variant readings have been explained, in this case by that peculiar complex of attitudes - personal, social and trade — which obtained for Congreve [. . .] in the first decade of the $18^{\text {th }}$ century" $(2002,225)$. One can quibble with McKenzie's insistence that the eclectic text does justice to rather than violates the historicity of the text. Zeller and McKenzie are at odds here in that McKenzie, somewhat unexpectedly, defends the historicity of the variants in the text, whereas Zeller argues for the historicity or "Befund" ["record"] of the authorized versions of the text (see Zeller 1995).

\section{The history of books and texts}

The fact remains that specific texts, existing in specific books, have a specific history which begins with their composition and revision, continues with their printing, publication and dissemination, and ends with their reception. In the first instance, editing in the time of the history of the book is "keeping the documentary in touch with the textual" (Eggert 2009, 157). But even when texts are faulty, they have a life of their own. Rather than simply removing errors, we may also want to ask, as Peter Shillingsburg advises, why a reader's responses to one text are - or are not - different from the his responses to another version of the same work $(2006,77)$. If the virtue of all bibliographical studies is, to quote again from

24 Again, Tanselle is in agreement with McKenzie: "[I]ntentionalist eclecticism is itself a manifestation of the historical drift of texts" (2005, 294). 


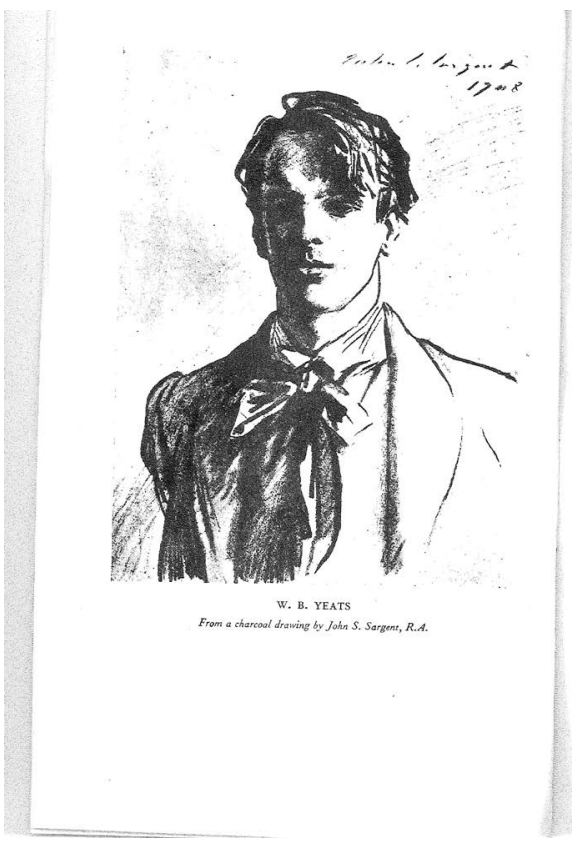

W. B. YEATS

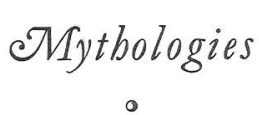

THE CELTIC TWILIGHT

THE SECRET ROSE STORIES OF RED HANRAHAN

ROSA ALCHEMICA

THE TABLES OF THE LAW

THE ADORATION OF THE MAGI

PER amica silentia lunar

Figure 4: W. B. Yeats, Mythologies, Macmillan (1959; reprinted 1984).

McKenzie's theoretical work, "to show the human presence in any recorded text" $(1999,29)$, then we must do this indeed for any text, not just for those closest to the top of the stemma. Critical editions should incorporate "the making of" of literary works more comprehensively than they currently do - and also, self-reflexively, their own making of. In the digital arena, several scholars have already put forward new ideas for this new type of edition. Ray Siemens' social edition, which envisages a new model of researcher engagement involving the user community in the construction of the digital edition to replace the old model, in which the final word rests exclusively with a small editorial team; Siemens and his colleagues see editions as a processs and editors as facilitators (Siemens at al., forthcoming). Edward Vanhoutte has repeatedly argued for the diversification of the functionality of digital editions: they should suit different audiences (e.g., Vanhoutte 2010; see also Lavagnino 2009, 65). That Vanhoutte's wish is not simply a return to textual pluriformity is made clear by Elena Pierazzo (2011), who distinguishes between the 

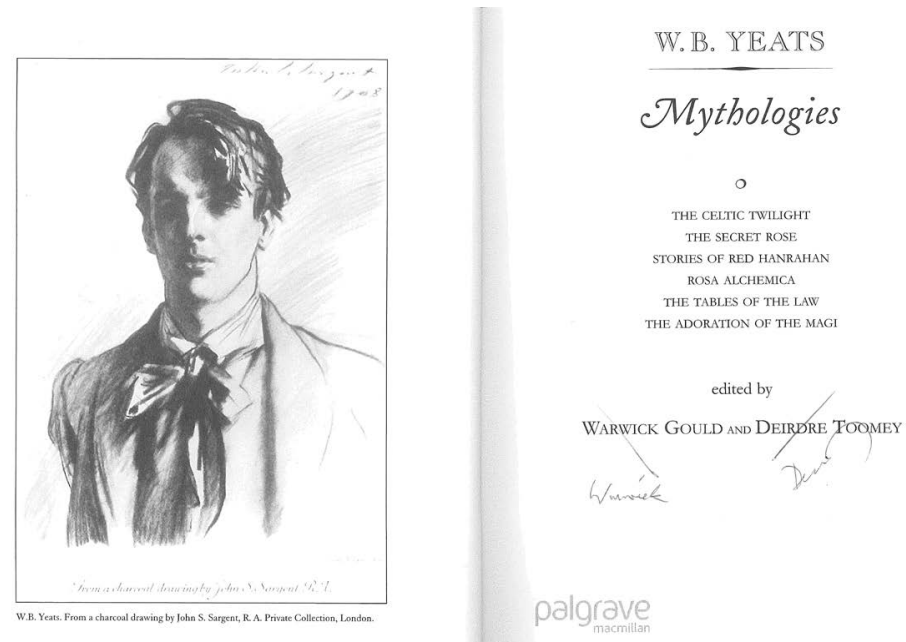

Figure 5: W. B. Yeats, Mythologies, edited by Warwick Gould and Deirdre Toomey, Palgrave Macmillan (2005).

display text and the embedded source files: variant editions exist in potentia within the TEI encoding and can be activated at will.

What critical editions in the time of the history of the book will look like is not a question I can answer specifically, but that it will build on the new directions in digital editing is certain. One can already see that the creation of new digital tools is also bringing about changes in editorial practice: it is apparent that in five or ten years we will be editing differently.

This prediction brings me, by way of conclusion, back to the issues of the granularity of editions and of McKenzie's sociology of the text. For McKenzie, textual scholarship was insufficiently concerned with the "material concerns of historical bibliography" considered from the "economic and social dimensions of production and Readership” (McKenzie 2002, 200). For generations, critical editors have performed a vital role and more often than not have performed it well. But what they have done is simply to produce editions - and texts - that are new and different from the old. By the very nature of what editors do, they push to a greater or lesser degree the old texts to 
the side. What they have not reckoned with, however, is the pastness of these texts, and that these texts do not exist independently from the books that contain them. Books look the way they do because of the involvement of other agents, such as the typesetters and designers that helped them into print. The non-textual elements of books, then, have expressive form, and we need to factor in these forms of expression, whether or not they came about with the author's sanction. It is time we learned how to read their language (McKenzie 2002, 207). I firmly agree with Paul Eggert when he advocates that "[e] ditorial experiments are needed" $(2009,152)$. To my knowledge only one print critical edition exists apart from McKenzie's own that has the characteristics of a social edition and that is the edition of Yeats's Mythologies prepared by Warwick Gould and Deirdre Toomey. This edition of Yeats's early prose stories tries to do justice not only to Yeats's final intention, but also to the intentions of his collaborators. Moreover, Mythologies is not just a collection of texts, but a book project that existed in ever-changing forms and incarnations; Mythologies grew over time as stories were collected and then re-collected in separate volumes, sometimes under different titles. Gould and Toomey represent the text of the Edition de Luxe that was in preparation with the Macmillan press in London but never realized on the grounds that this edition was to be, in Yeats's mind, the expression of his permanent self. To top it all, the layout of the new edition, published by Palgrave Macmillan, pays homage to the original Macmillan format by replicating Yeats's favourite typeface, Caslon Old Style, in the text and running headers and by its imitation of the title page from the standard edition (Figures 4 and 5).

This example shows that the material aspects of texts and books must not by necessity be suppressed in a scholarly edition. Although the edition of Mythologies by Gould and Toomey is a new book, its design references the time and place of the work's original production. An edition like this mediates its text differently than the ordinary scholarly edition. It does not purport to exist outside of its own interface.

The digital environment, rather than diminishing the granularity of the text, increases it. This statement is becoming self-evident in those areas of textual transmission in which the physical form of the book is as important as the text that it contains. Digital editions of medieval manuscripts or of modernist magazines cannot really avoid 
the forms of their original design. One can only hope that scholarly editions of texts and books that have a less spectacular design will nonetheless follow suit in rendering some of their original historical forms.

\section{Bibliography}

Chandler, Daniel. 2007. Semiotics: The Basics. $2^{\text {nd }}$ ed. Oxford, New York: Routledge.

Chartier, Roger. 1989. "Texts, Printing, Readings". In Lynn Hunt (ed.), The New Cultural History. Berkeley and Los Angeles: University of Berkeley Press, pp. 154-175

Chaudhury, Sukanta. 2010. The Metaphysics of Text. Cambridge: Cambridge University Press.

Deming, Robert H. 1997. James Joyce: The Critical Heritage. Vol. 1: 1907-27. London: Routledge.

Eggert, Paul. 2009. Securing the Past: Conservation in Art, Architecture and Literature. Cambridge: Cambridge University Press.

Eliot, T. S. 2006. The Annotated Waste Land with Eliot's Contemporary Prose, $2^{\text {nd }}$ ed. New Haven and London: Yale University Press.

—. 2009. The Letters of T. S. Eliot. 2 vols. Eds. Valerie Eliot and Hugh Haughton. London: Faber and Faber.

Finkelstein, David and Alistair McCleery. 2005. An Introduction to Book History. New York and London: Routledge.

— - eds. 2006. The Book History Reader. $2^{\text {nd }}$ ed. London: Routledge.

Gabler, Hans Walter. 2008. Argument into Design: Editions as a SubSpecies of the Printed Book. London: School of Advanced Study, University of London. <http://www.ies.sas.ac.uk/sites/default/files/ files/Publications/Coffin \% 20lectures/HWG\% 20Coffin $\% 20$ 2008.pdf >. [Accessed 12 April 2012].

Galey, Alan. 2010. "The Human Presence in Digital Artefacts". In Willard McCarty (ed.) Text and Genre in Reconstruction: Effects of Digitalization on Ideas, Behaviours, Products and Institutions. Cambridge: Open Book Publishers, pp. 93-117.

Gould, Warwick. 1989. "The Definitive Edition: A History of the Final Arrangements of Yeats's Work". In A. Norman Jeffares (ed.), Yeats's Poems. London and Basingstoke: Macmillan Papermac, pp. 706-749. 
- 1994. "W. B. Yeats and the Resurrection of the Author". The Library, $6^{\text {th }}$ ser., 16, pp. 101-134.

Kirschenbaum, Matthew G. 2002. "Editing the Interface: Textual Studies and First Generation Electronic Objects". Text, 14, pp. $15-51$.

Lavagnino, John. 2009. “Access”. Literary and Linguistic Computing, 24, 63-76.

Material Texts Network. London: Birkbeck College, University of London, 2011. <http://www.bbk.ac.uk/arts/our-research/centres/the-material-texts-network>. [Accessed 12 March 2012].

McCue, Jim. 2006. "Editing Eliot”. Essays in Criticism, 56, pp. 1-27.

McGann, J. J. 1991. The Textual Condition. Princeton: Princeton University Press.

McKenzie, D. F. 1984. "The Sociology of a Text: Orality, Literacy and Print in Early New Zealand". The Library, 6th ser., 6, pp. 333-65.

- 1999. Bibliography and the Sociology of Texts. $2^{\text {nd }}$ ed. Cambridge: Cambridge University Press.

—. 2002. Making Meaning: "Printers of the Mind" and Other Essays. Eds. Peter D. MacDonald and Michael Suarez. Amherst, Boston: University of Massachusetts Press.

—. 2011. "Textual Introduction”. In D. F. Mckenzie and C. Y. Ferdinand (eds.). The Works of William Congreve. Vol. 1. Oxford: Oxford University Press, pp. xvii-xxxiii.

Nutt-Kofoth, Rüdiger. 2004. “Author's Reading-Author's Literary Production: Some Reflections on the Editing of Reading Notes in German Critical Editions". In Dirk Van Hulle and Wim Van Mierlo (eds.), Reading Notes. Special issue of Variants, 2/3, pp. 293-302.

Pierazzo, Elena. 2011. "A Rationale of Digital Documentary Editions". Literary and Linguistic Computing, 26, pp. 463-47.

Plachta, Bodo. 2007. "More Than Mise-en-Page: Book Design and German Editing”. In Wim Van Mierlo (ed.), Textual Scholarship and the Material Book. Special issue of Variants, 6, pp. 85-105.

Shillingsburg, Peter L. 1997. Resisting Texts: Authority and Submission in Constructions of Meaning. Ann Arbor, Mich.: University of Michigan Press.

— 2006. From Gutenberg to Google: Electronic Representations of Literary Texts. Cambridge: Cambridge University Press. 
Siemens, Raymond, et al. Forthcoming. "Toward Modeling the Social Edition: An Approach to Understanding the Electronic Scholarly Edition in the Context of New and Emerging Social Media”. Literary and Linguistic Computing.

Storey, H. Wayne. 2006. "Dirty Manuscripts and Textual Cultures: Introduction to Textual Cultures 1.1". Textual Cultures, 1(1), pp. $1-4$.

Tanselle, G. Thomas. 2005. Textual Criticism since Greg: A Chronicle, 1950-2000. Charlottesville: The Bibliographical Society of the University of Virginia.

Vandendorpe, Christian. 2009. From Papyrus to Hypertext: Toward the Universal Digital Library. Trans. Phyllis Aronoff and Howard Scott. Chicago: University of Illinois Press.

Vanhoutte, Edward. 2010. "Defining Electronic Editions: A Historical and Functional Perspective". In Willard McCarty (ed.), Text and Genre in Reconstruction: Effects of Digitalization on Ideas, Behaviours, Products and Institutions. Cambridge: Open Book Publishers, pp. 119-144.

Van Mierlo, Wim. 2007. "Introduction”. In Wim Van Mierlo (ed.), Textual Scholarship and the Material Book. Special issue of Variants, 6 , pp. 1-12.

"Welcome to the Cambridge Centre for Material Texts". In Centre for Material Texts: A New Forum for the Study of the Word in the World. Cambridge: Cambridge University, 2009. <http://www.english. cam.ac.uk/cmt/>. [Accessed 12 March 2012].

Willison, I. R., 2006. "The History of the Book as a Field of Study within the Humanities". SAS-Space e-Repository. London: School of Advanced Study. <http://sas-space.sas.ac.uk/8/>. [Accessed 9 March 2012].

Yeats, W. B. 1989. Yeats's Poems. Ed. A. Norman Jeffares. London and Basingstoke: Macmillan Papermac.

—. 1997. The Poems. Ed. Richard J. Finneran. $2^{\text {nd }}$ ed. New York: Scribner.

—. 2005. Mythologies. Eds. Warwick Gould and Deirdre Toomey. Houndmills, Basingstoke: Palgrave Macmillan.

Zeller, Hans. 1995. "Record and Interpretation: Analysis and Documentation as Goal and Method of Editing". Hans Walter Gabler et al. (eds.) Contemporary German Editorial Theory. Ann Arbor: University of Michigan Press, pp. 17-58. 
